\title{
Deep Peak Load Regulation Compensation Mechanism of Thermal Power Units Incorporating the Change of Object and the Capability of Subject of Peak Load Regulation
}

\author{
Zhen'an Zhang ${ }^{1}$, Junzhe Lei ${ }^{1}$, Zicheng Zhou ${ }^{2}$, Quansheng Zhu ${ }^{1}$, Haixia Wang ${ }^{2}$, Quan $\mathrm{Lv}^{2}$, Weidong $\mathrm{Li}^{2}$ \\ ${ }^{1}$ Electric Power Research Institute of State Grid Henan Electric Power Company, Zhengzhou 450052, China \\ ${ }^{2}$ College of Electrical Engineering, Dalian University of Technology, Dalian 116024, China
}

\begin{abstract}
A deep peak load regulation compensation mechanism of thermal power units is presented to encourage the units to actively participate in peak load regulation and improve their peaking capability. The compensation mechanism consists of two sections. In the first section, the method of dividing basic peak load regulation and deep peak load regulation is determined base on the approved peaking rate of thermal power units. In the second section, the peaking compensation model of thermal power units incorporating the change of peaking demand and the difference of peaking capability is given. In the model, the peaking demand of power grid is used to correct the peaking compensation standard, the peaking capability of thermal power unit is used to correct the peaking compensation cost. The proposed compensation mechanism is impartial for all thermal power units and is effective for units to actively participate in the peak load regulation and to improve their peaking capability. A case study demonstrates the rationality of the compensation mechanism.
\end{abstract}

Keywords-peak load regulation compensation mechanism; deep peak load regulation; peaking demand of power grid; peaking capability of thermal power units

\section{INTRODUCTION}

With the adjustment of the national economic structure and the load peak-valley difference increases year by year, the pressure of peak load regulation of power grid is more and more severe. Meanwhile, the large-scale integration of wind energy into power grid has occupied the capacity of thermal power units, which leads to a decrease in peaking capability of power grid. And the wind power output with the characteristics of uncertainty, randomness and significant anti-peak also brought new challenges to peak load regulation [1]-[4].

Peak load regulation is of great significance to the national economy since it is directly related to the safe and stable and economic operation of the power system. Faced the severe peaking problem, the State Energy Regulatory Commission issued the "Provisions on the Administration of Grid-connected Power Plants" and "Interim Measures for the Administration of Auxiliary Service for Grid-connected Power Plants". Then the regional power grids respectively formulated the detailed rules for the implementation of the administration of grid-connected power plants and the detailed rules for the implementation of the administration of auxiliary service for grid-connected power plants (referred to as the "two Detailed Rules"). Aiming at peak load regulation auxiliary service, the compensation mechanism is established in these documents to encourage the units to actively participate in peak load regulation. Compensation mechanism includes the division of basic peak load regulation and deep peak load regulation, the determination of compensation model and the allocation of compensation cost and so on.

For the division of basic peak load regulation and deep peak load regulation, the existing compensation mechanism is based on the rated capacity of a certain percentage of the units as the critical peaking rate. The no-oil-consumption stable combustion limit and maximum load-reducing rate are chosen as indicators and the method of the division of basic peak load regulation and deep peak load regulation base on convex hull barycenter-seeking is proposed in [5] to solve the problem of the qualitative classification and lack of theoretical support of the existing division method. However, during the valley load period, the unit is always in a stable low output condition, so it can't achieve the corresponding load-reducing rate and it can't obtain the peaking compensation cost, which is contrary to the original purpose of peak load regulation compensation mechanism to encourage the units to actively participate in peak load regulation during the valley load period. Aiming at the problem of the single division of the existing classification, it is proposed that different division limits of basic peak load regulation and deep peak load regulation should be taken and adopted for different capacity of units in [6]. And in [7], a method to extend the range of peak load regulation compensation for high energy consumption units under the condition of ensuring the compensation range of low power consumption unit is proposed. But this method is not conducive to energy saving policy requirements.

For the peak load regulation compensation model, the existing compensation mechanism is divided into the deep peak load regulation compensation and start-stop peak load regulation compensation. Deep peak load regulation compensation is based on the contributing energy of deep peak load regulation and the compensation standard of unit energy as peak load regulation compensation cost. However, this model is a highly uniform compensation model, it can't reflect 
the differences between units and difficult to improve the enthusiasm of the units to participate in peak load regulation. In [6], the maximum peaking rate of the unit is used as the peaking capability of the thermal power unit, and a compensation model of peak load regulation auxiliary service is proposed considering the degree of realization of peaking capability. On the basis of [6], reference [7] defined peaking capability of thermal power units with the maximum peaking rate and unit ramp rate as indicators and the peaking capability and the degree of realization of peaking capability are taken as the positive coefficient of peak load regulation. Then a compensation model of peak load regulation considering the positivity of peak load regulation is established.

In addition to improve the existing compensation mechanism of peak load regulation, there are a large number of literature have studied the new model of the compensation mechanism. In [8], the peaking capability of hydropower units and thermal power units can be characterized by start-stop time, output rate, output amplitude, and water discharge of hydro units for peak load regulation. Then, a fuzzy comprehensive evaluation method for peaking capability is proposed and the incentive mechanism of peaking capability is established to stimulate the units to provide peaking service and improve their peaking capability. The compensation of hydropower units involved in peak load regulation is studied in [9] and [10]. In the context of energy-saving power generation dispatch, a novel method is proposed to establish the peak load regulation mechanism with the concept of equivalent available load rate in [11].

China still has a large number of small units to participate in the system operation, and they play an important role in peak load regulation of power grid. Usually the minimum technical output of thermal power units are as follows: 200MW: 55\% ECR, 300MW (350MW): 47\% ECR, 600MW and above: 43\% ECR [12].

It can be seen that there is a large difference in the peaking range of units with different capacities. The larger the unit capacity is, the greater the peaking range is. In accordance with the existing division method which is based on unit rated capacity, it is difficult for small units to obtain the peaking compensation even if they fully involved in peak load regulation. So the division of basic peak load regulation and deep peak load regulation should take into account the incentive of small units. Considering the inevitable connection between the object and the subject of peak load regulation, the existing compensation model should be included in the object of peak load regulation, the peaking demand, and subject of peak load regulation, the peak load regulation power. And should consider the influence of the change of peaking demand and the difference of peaking capability of the units.

Therefore, the division method of basic peak load regulation and deep peak load regulation is determined base on the approved peaking rate which is the lowest standard peaking range according to lowest stable load of thermal power unit. Then we correct the peaking compensation standard by the peaking demand of power grid and correct the peaking compensation costs by the peaking capability of thermal power units, and a deep peak load regulation compensation model of thermal power units is established considering the peaking demand and the peaking capability.

\section{THE DiVISION OF BASIC PEAK LOAD REgUlation AND DEEP PEAK LOAD REGULATION}

In order to make reasonable compensation for small units and to encourage the positivity of peak load regulation of small units, we present a method to determine the basic peak load regulation and deep peak load regulation base on the approved peaking rate of thermal power units.

The peaking rate $r_{i, t}$ of the unit $i$ at time $t$ is defined as

$$
r_{i, t}=\frac{P_{\mathrm{max}, i}-P_{i, t}}{P_{\max , i}}
$$

where $P_{\text {max }, i}$ is the maximum technical output (rated output), $P_{i, t}$ is the output of the unit $i$ at time $t$.

Correspondingly, the approved peaking rate $r_{\max , i}^{s}$ of the unit $i$ is expressed by

$$
r_{\mathrm{max}, i}^{\mathrm{s}}=\frac{P_{\mathrm{max}, i}-P_{\min , i}^{\mathrm{s}}}{P_{\max , i}}
$$

where $P_{\min , i}^{s}$ is the approved minimum technical output of the unit $i$.

The approved minimum technical output of the unit is the standard minimum stable load determined by the unit's boiler design specification, boiler characteristics test report and the unit's operating record.

In order to ensure the reasonable compensation for the units with small peaking range, a proportionality factor $\rho$ (less than 1) can be introduced into the unit's approved peaking rate to produce the critical peaking rate $r_{c, i}$ of the basic peak load regulation and the deep peak load regulation, that is

$$
r_{c, i}=\rho r_{\max , i}^{s}
$$

At this time, each unit has a certain deep peaking range, that is interval $\left[r_{c, i}, r_{\text {max }, i}^{s}\right]$. As long as the unit's output in this interval, it is can be regarded as the participation of deep peak load regulation, and peaking compensation can be obtained.

The determination of $\rho$ should guarantee that the interests of units with large peaking range will not be damaged because of the new division. In this paper, we use the maximum approved peaking rate in the system and the critical peaking rate in the current provisions to determine the specific value of $\rho$, that is 


$$
\rho=\frac{r_{c}}{\max _{i} r_{\max , i}^{s}}
$$

For instance, a system stipulated $r_{c}=50 \%$, while $\max _{i} r_{\max , i}^{s}=55 \%$, then $\rho=\frac{r_{c}}{\max _{i} r_{\max , i}^{s}}=90.91 \%$.

If the degree of participation of peak load regulation $\delta_{i, t}$ of the unit $i$ at time $t$ is defined as

$$
\delta_{i, t}=\frac{r_{i, t}}{r_{\max , i}^{s}}
$$

We can determine whether it is involved in deep peak load regulation according to its degree of participation. That is, if $\delta_{i, t}>\rho$, the unit $i$ is in the condition of deep peak load regulation and if $\delta_{i, t}<\rho$, the unit $i$ is in the condition of basic peak load regulation.

\section{THE COMPENSATION MODEL OF DEEP PEAK LOAD REgUlATION FOR THERMAL POWER UNITS}

For the problem of peak load regulation of power grid, from the perspective of dialectic, peaking demand of power grid is the object of peak load regulation, and thermal power units that assume the main task of peak load regulation are the subject of peak load regulation. The subject of peak load regulation (peaking units) and the object of peak load regulation (peaking demand) are interrelated and interact. When the peaking demand of power grid increases, objectively shows that peak load regulation is difficult. The subject of peak load regulation need to pay more to meet the peaking demand and peaking costs will also increase. At this point appropriate to increase the compensation cost for peaking service, which can effectively stimulate the initiative of the unit current participation in peak load regulation, and can promote the peaking capability in the future to ease the peaking pressure of power grid.

When the subject of peak load regulation improves its peaking capability, it can meet greater peaking demand of power grid and is conducive to peak load regulation. So the compensation of units with higher peaking capability should be increased.

The existing compensation model of deep peak load regulation can be expressed by

$$
M_{i, \Delta t}=Q_{i, \Delta t} * S
$$

where $M_{i, \Delta t}$ is the obtained compensation cost of the unit $i$ in the time of $\Delta t, Q_{i, \Delta t}$ is the contributing energy of deep peak load regulation of the unit $i$ in the time of $\Delta t, S$ is the compensation standard of unit contributing energy of deep peak load regulation.
In this model $S$ usually is a fixed value in a power grid, not change with the peaking demand of the power grid, which can not fully reflect the objective influence of the object of peak load regulation on peaking costs. $Q_{i, \Delta t}$ is related to units and time, and to a certain extent reflects the participation of the subject of peak load regulation, but it is multiplied by the fixed value $S$. For the subject of peak load regulation with different peaking capabilities, the results present different quality but with the same price situation, which is lack of incentive for peaking unit with higher peaking capability.

To this end, the following deep peak load regulation compensation model is established.

$$
M_{i, \Delta t}=U P C_{i, \Delta t}^{c} * Q_{i, \Delta t} * \beta_{m} * S
$$

where $U P C_{i, \Delta t}^{c}$ is the peaking capability coefficient of the unit $i$ in the time of $\Delta t, \beta_{m}$ is peaking demand coefficient of power grid during the month of $m$.

As the peaking demand coefficient of power grid is the demand coefficient to objectively describe the overall system, and has nothing to do with units and time, it can be used for the correction of the compensation standard unit of energy. Unit's peaking capability coefficient is related to units and time, it can be used for the correction of the peaking compensation cost.

\section{A. Determination of Peaking Demand Coefficient of Power Grid}

The size of the peaking demand coefficient of power grid reflects the degree of peaking compensation standard corresponding to the change of the peaking demand of power grid. Its value should be stable during each billing cycle to generate a stimulus signal for the next billing cycle, and to motivate each unit to actively participate in deep peak load regulation.

In the existing peaking compensation mechanism, peaking compensation is settled on a monthly basis. So the month should be the unit of time to determine the peaking demand coefficient of power grid. As the day is the unit of time to arrange peak load regulation, so this power generation plan faces the load peak-valley difference per day. Therefore, when using the month to be the time scale to determine the peaking demand coefficient of power grid, we should count the overall monthly load peak-valley difference. The peak-valley difference rate can reasonably compare the relative size of daily peaking demand per day and is not limited to the difference of the absolute value of the peak-valley difference and can reflect the real size of the peaking demand in a better way. So the peak-valley difference rate is used as the daily basic statistical value. The greater the mean of the peak-valley difference rate is, the greater the peaking demand is. The standard deviation of the peak-valley difference rate is greater, namely the change of the peak-valley difference rate is larger. So it is more difficult for dispatch department to arrange a reasonable power generation plan, which means the corresponding peaking demand is greater. Comparing the numerical characteristics of the current month with the corresponding numerical 
characteristics of the previous year, we can get the relative size of peaking demand. Because the monthly mean of the load peak-valley difference rate is different, we can not directly compare their standard deviation. Then the standard deviation coefficient is used to represent the size of standard deviation on the unit mean.

To sum up, $\beta_{m}$ can be determined by

$$
\beta_{m}=\frac{\bar{\mu}_{m}}{\bar{\mu}_{l y}} * \frac{\sigma_{m}}{\bar{\mu}_{m}} / \frac{\sigma_{l y}}{\bar{\mu}_{l y}}=\frac{\sigma_{m}}{\sigma_{l y}}
$$

where $\bar{\mu}_{m}$ is the mean of the peak-valley difference rate of the current month, $\bar{\mu}_{l y}$ is the mean of the peak-valley difference rate of the last year, $\sigma_{m}$ is the standard deviation of the peakvalley difference rate of the current month, $\sigma_{l y}$ is the standard deviation of the peak-valley difference rate of the last year, $\sigma_{m} / \bar{\mu}_{m}$ is the standard deviation coefficient of the peak-valley difference rate of the current month, $\sigma_{l y} / \bar{\mu}_{l y}$ is the standard deviation coefficient of the peak-valley difference rate of the last year.

\section{B. Determination of the Peaking Capability Coefficient of Unit}

The peaking capability of unit can usually be characterized by the unit peaking range (maximum peaking capacity) and ramp rate. The larger peaking range can accommodate larger load peak-valley difference, and higher ramp rate can track faster load changes.

As the large unit relative to the small unit, the peaking range and ramp rate gap between the larger, so there is no direct comparability. We can get the relative index value using rated capacity of the unit itself as reference value. At this point, the two indicators are given by

$$
\begin{gathered}
r_{\max , i}=\frac{P R_{i}}{P_{\max , i}} \\
R A M P_{s, i}=\frac{R A M P_{i}}{P_{\max , i}}
\end{gathered}
$$

where $P R_{i}$ is the peaking range of the unit $i$, that is the maximum peaking capacity, $P R_{i}=P_{\max , i}-P_{\min , i}, r_{\max , i}$ is the relative index value of the peaking range, that is the maximum peaking rate of the unit $i, R A M P_{i}$ is the ramp rate of the unit $i$, $R A M P_{s, i}$ is the relative index value of the ramp rate.

It is a comprehensive evaluation problem to apply the two indexes to evaluate the peaking capability of the unit The commonly used comprehensive evaluation methods include analytic hierarchy process, fuzzy comprehensive evaluation, data envelopment analysis, artificial neural network evaluation, gray comprehensive evaluation and so on [13]. The gray comprehensive evaluation method base on gray relational analysis has the advantages of low data requirement, simple calculation and easy to understand. In this paper, the method of gray comprehensive evaluation is used to evaluate the peaking capability of the unit.

In order to evaluate the peaking capability of the unit, the concrete evaluation steps are as follows:

1) Determine the index sequence and determine the optimal index set

When the system load is in the rising state, the up-ramp $R A M P_{s, i}^{U}$ is used as the evaluation index, and the maximum of each index value is selected into the optimal index set. At this time

$$
\begin{gathered}
X_{i}=\left\{r_{\max , i}, R A M P_{s, i}^{U}\right\} \\
X_{0}=\left\{\max _{i} r_{\max , i}, \max _{i} R A M P_{s, i}^{U}\right\}
\end{gathered}
$$

When the system load is in the descending state, the downramp $R A M P_{s, i}^{D}$ is used as the evaluation index, and the maximum of each index value is selected into the optimal index set. At this time

$$
\begin{gathered}
X_{i}=\left\{r_{\max , i}, R A M P_{s, i}^{D}\right\} \\
X_{0}=\left\{\max _{i} r_{\max , i}, \max _{i} R A M P_{s, i}^{D}\right\}
\end{gathered}
$$

2) Determine the indicator weights

The method of combination weighting is used to assign weights to each index. First, the subjective weight and the objective weight should be determined. This paper puts forward the method of weighting the subjective weight base on the degree of peaking demand from the actual problem of comprehensive evaluation of the peaking capability.

On the one hand, the peaking demand of power grid at time $t, P D_{P R, t}$, is the difference of peak load and current load during dispatching period, that is, the demand of load for peaking capacity of power grid. On the other hand, the peaking demand of power grid at time $t, P D_{R, t}$ is the demand of the change of load for ramp rate of power grid between time $t$ and time $t+1$.

$P D_{P R, t}$ at time $t$ can be expressed by

$$
P D_{P R, t}=P L_{\max }-P L_{t}
$$


where $P L_{\max }$ is the peak load during dispatching period, $P L_{t}$ is the load of power grid at time $t$.

While $P D_{R, t}$ can be divided into the demand of up-ramp $P D_{U R, t}$ and the demand of down-ramp $P D_{D R, t}$. They are given by

$$
\begin{array}{ll}
P D_{U R, t}=P L_{t+1}-P L_{t} & \left(P L_{t+1}>P L_{t}\right) \\
P D_{D R, t}=P L_{t}-P L_{t+1} & \left(P L_{t+1}<P L_{t}\right)
\end{array}
$$

Correspondingly, the peaking demand degree of load for peaking capacity of power grid $P D D_{P R, t}$ is defined by

$$
P D D_{P R, t}=\frac{P D_{P R, t}}{S A P C}
$$

where SAPC is the available peaking capacity.

The peaking demand degree of the load for ramp rate of power grid $P D D_{R, t}$ is defined by

$$
P D D_{R, t}=\frac{P D_{R, t}}{S R}
$$

where $S R$ is the sum of the ramp rate of the starting units.

The two aspects of the peaking demand degree of the power grid respectively show the degree of demand for peaking range and ramp rate. The changing demand of load is connected with the peaking capability of the unit when using the peaking demand degree of the power grid as the subjective weight for peaking capability evaluation. When the demand degree of load for peaking capacity of power grid is high, the maximum peaking rate index is called a higher weight, and then the unit with larger maximum peaking rate can obtained more compensation cost in the compensation mechanism considering the peaking capability of unit. When the demand degree of load for ramp rate of power grid is high, the ramp rate index is called a higher weight, and then the unit with larger ramp rate can obtained more compensation cost in the compensation mechanism considering the peaking capability of unit.

Therefore, the expression values for the two aspects of the peaking demand degree of the power grid can be normalized and used as the weights for the two indicators of peaking capability comprehensive evaluation. That is, the subjective weight vector is given by

$$
\boldsymbol{W}_{1, t}=\left[P D D_{P R, t}^{\prime}, P D D_{R, t}^{\prime}\right]
$$

where $P D D_{P R, t}^{\prime}, P D D_{R, t}^{\prime}$ is the results of the normalization of $P D D_{P R, t}$ and $P D D_{R, t}$.
In this paper, the entropy weight method is used to obtain the objective weight. It is a practical objective weighting method to judge the weight of the index by the amount of information contained in the entropy of different indexes. The objective weight vector is $\boldsymbol{W}_{2}$.

Combining the subjective weight represented by peaking demand degree with the objective weight obtained by entropy weight method, we get the combined weight. This combined weight not only to reflect the demand of load for the unit's peaking capability, but also contains the data itself information. The combined weight at time $t$ can be calculated by [14]

$$
W_{i, t}=\alpha W_{1, i, t}+(1-\alpha) W_{2, i} \quad i=1,2
$$

where $W_{1, i, t}$ is the subjective weight represented by peaking demand degree at time $t, W_{2, i}$ is the objective weight obtained by entropy weight method, $\alpha$ is depends on the correlation of $W_{1, i, t}$ and $W_{2, i}$, and $0 \leq \alpha \leq 1$, it can be obtained from the Kendall correlation coefficient.

3) Calculate the correlation coefficient of each index to get the evaluation matrix $\boldsymbol{E}$

4) Calculate gray weighted correlation degree at time $t$.

$$
\boldsymbol{\Gamma}_{t}=\boldsymbol{W}_{t} \boldsymbol{E}^{\boldsymbol{T}}=\left[\gamma_{1, t}, \gamma_{2, t}, \ldots, \gamma_{n, t}\right]
$$

The gray weighted correlation degree vector is the result of comprehensive evaluation. The greater the correlation degree is, the stronger the peaking capacity is. In order to adjust the result of the comprehensive evaluation for peaking capability as the incentive coefficient of compensation costs, $\gamma_{i, t}$ can be map to the interval $[1, \varphi]$, turns to $U P C_{i, \Delta t}^{c}$, through the method of linear mapping, where $\varphi$ is the maximum value of excitation coefficient interval and its value depends on the relative importance of peaking capability of units. We recommend getting its value between 1.2 and 1.3.

\section{CASE STUDY}

The test case is a simple system with 10 generators and the generating set data are shown in Table I and the load data are shown in Table II.

In this case, we assume that the approved minimum technical output is the minimum output of the unit, then $\rho=0.6667$, and according to a system of actual load data $\beta_{m}=\sigma_{m} / \sigma_{l y}=1.108$. And $S=100$ ( $¥ / \mathrm{MWh}$ ), taking $\varphi=1.3$. According to the results of economic dispatch, the 1-3 units participate in deep peak load regulation. Period 6 is in valley load, taking this time period as an example, the compensation results during period 6 of the 1-3 units are shown in Figure I and the all-day compensation results of the 1-3 units are shown in Figure II. 
TABLE I. PARAMETERS OF UNITS

\begin{tabular}{|c|c|c|c|c|c|c|c|}
\hline Unit & $\begin{array}{c}P_{\text {max }, i} \\
(\mathrm{MW})\end{array}$ & $\begin{array}{c}P_{\min , i} \\
(\mathrm{MW})\end{array}$ & $\begin{array}{c}a_{i} \\
\left(\$ / \mathrm{MW}^{2}\right)\end{array}$ & $\begin{array}{c}b_{i} \\
(\$ / \mathrm{MW})\end{array}$ & $\begin{array}{c}c_{i} \\
(\$)\end{array}$ & $\begin{array}{c}U R_{i} \\
(\mathrm{MW} / \mathrm{h})\end{array}$ & $\begin{array}{c}D R_{i} \\
(\mathrm{MW} / \mathrm{h})\end{array}$ \\
\hline 1 & 520 & 250 & 0.00127 & 1.3954 & 105 & 260 & 260 \\
\hline 2 & 320 & 120 & 0.00289 & 1.2643 & 49 & 150 & 150 \\
\hline 3 & 280 & 80 & 0.00261 & 1.35 & 72 & 110 & 110 \\
\hline 4 & 200 & 80 & 0.00148 & 1.2136 & 82 & 100 & 100 \\
\hline 5 & 150 & 50 & 0.00135 & 1.3285 & 100 & 60 & 60 \\
\hline 6 & 150 & 50 & 0.00212 & 1.54 & 29 & 50 & 50 \\
\hline 7 & 120 & 30 & 0.00382 & 1.4 & 32 & 60 & 60 \\
\hline 8 & 110 & 30 & 0.00393 & 1.35 & 40 & 45 & 45 \\
\hline 9 & 80 & 20 & 0.00396 & 1.5 & 25 & 30 & 30 \\
\hline 10 & 60 & 20 & 0.0051 & 1.4 & 15 & 20 & 20 \\
\hline
\end{tabular}

TABLE II. LOAD DATA

\begin{tabular}{|c|c|c|c|c|c|}
\hline $\mathbf{T}$ & $\mathbf{P}(\mathbf{M W})$ & $\mathbf{T}$ & $\mathbf{P}(\mathbf{M W})$ & $\mathbf{T}$ & $\mathbf{P}(\mathbf{M W})$ \\
\hline 1 & 1502.34 & 9 & 1428.59 & 17 & 1546.41 \\
\hline 2 & 1410.51 & 10 & 1535.24 & 18 & 1464.62 \\
\hline 3 & 1357.14 & 11 & 1660.17 & 19 & 1392.86 \\
\hline 4 & 1303.57 & 12 & 1785.83 & 20 & 1482.08 \\
\hline 5 & 1269.64 & 13 & 1870.54 & 21 & 1517.86 \\
\hline 6 & 1285.72 & 14 & 1785.36 & 22 & 1489.29 \\
\hline 7 & 1321.43 & 15 & 1732.28 & 23 & 1392.56 \\
\hline 8 & 1328.47 & 16 & 1625.33 & 24 & 1321.43 \\
\hline
\end{tabular}

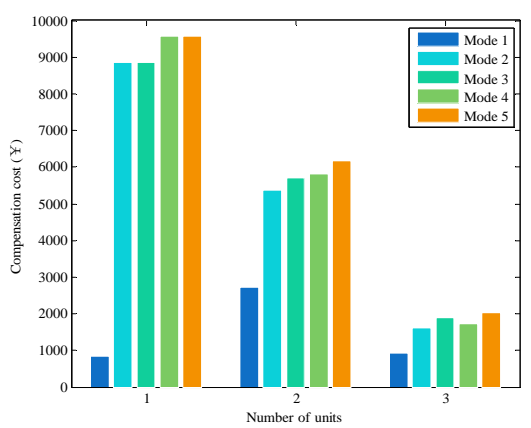

FIGURE I. THE COMPENSATION RESULTS IN PERIOD 6 OF THE 1-3 UNITS

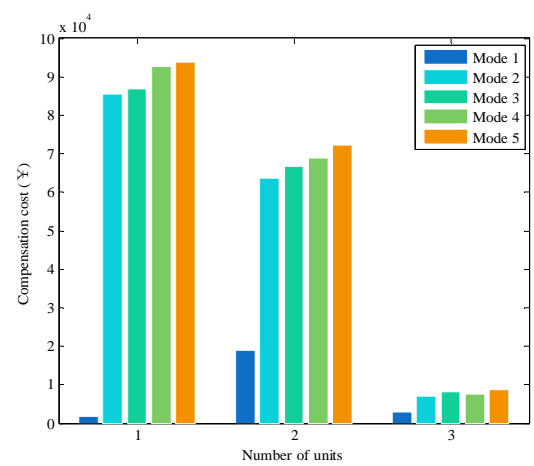

FIGURE II. THE ALL-DAY COMPENSATION RESULTS OF THE 1-3 UNITS

Mode 1 is the existing compensation mechanism. Mode 2 is the compensation mechanism in this paper does not take into account the peaking capability coefficient and the peaking demand coefficient. Mode 3 is the compensation mechanism in this paper does not take into account the peaking demand coefficient. Mode 4 is the compensation mechanism in this paper does not take into account the peaking capability coefficient. Mode 5 is the compensation mechanism in this paper.

As the large capacity and the low average load rate of unit 1 , the division method of basic peak load regulation and deep peak load regulation has a greater impact on the amount of compensation. And because of its peaking capability in the period 6 is the lowest, so whether the compensation model to consider peaking capability has no effect on its compensation amount. Its peaking capacity is not always the lowest in each period of the day. Therefore, the amount of all-day compensation has changed after taking into account the peaking capacity.

Unit 2 and unit 3 under different modes show different trends, mainly due to peaking capacity of unit 3 is stronger. So unit 3 has a greater impact on the amount of compensation and its rate-of-change of compensation amount is the most.

\section{CONCLUSION}

The division of basic peak load regulation and deep peak load regulation base on the approved peaking rate can ensure that each unit has the opportunity to participate in the deep peak load regulation and enhance the positive initiative of the unit to participate in peak load regulation.

The compensation standard of unit energy is modified by introduced peaking demand coefficient to realize the close connection between the subject of peak load regulation and the object of peak load regulation, which is conducive to guide the unit according to the objective peaking demand to actively participate in the peak load regulation.

The peaking capability coefficient of the unit is used to revise the peaking compensation cost, so that the unit with strong peaking capability can obtain more compensation cost, which is conducive to stimulate the unit to improve its peaking capability and to ensure safe and stable operation of the power grid.

\section{REFERENCES}

[1] XIAO Chuang-ying, WANG Ning-bo, DING Kun, ZHI Jing, "System Power Regulation Scheme for Jiuquan Wind Power Base,” Proceeding of the CSEE, vol. 30, no. 10, pp. 1-7, Apr. 2010.

[2] XIN Song-xu , BAI Jian-hua , GUO Yan-heng, "Study on Wind Power Characteristics of Jiuquan Wind Power Base,” Energy Technology and Economics, vol. 22, no. 12, pp. 16-20, Dec. 2010.

[3] ZHANG Hongyu, YIN Yonghua, SHEN Hong, HE Jian, ZHAO Shanshan, "Peak-load Regulating Adequacy Evaluation Associated With Large-scale Wind Power Integration,” Proceeding of the CSEE, vol. 31, no. 22, pp. 26-31, Aug. 2011.

[4] YANG Hong, LIU Jian-xin, YUAN Jin-sha, "Research of Peak Load Regulation of Conventional Generators in Wind Power Grid," Proceeding of the CSEE, vol. 30, no. 16, pp. 26-31, Jun. 2010.

[5] WANG Peng, ZHANG Lingling, LIANG Lin, LIU Hanwei, “A Method for Division of Paid Peak-regulation and Free Peak-regulation for Thermal Power Units,” Automation of Electric Power Systems, vol. 34 no. 9, pp. 87-90, May. 2010. 
[6] ZHAO Xiaoli, WANG Wei, ZHAO Yue, WU Qiubing, “A Model of Compensation Mechanism on Peak-regulating Ancillary Services Based on Capacity Variance Across Thermal Power Units," Automation of Electric Power Systems, vol. 37, no. 4, pp. 57-61, Feb. 2013.

[7] LI Yanqing, LI Haoshan, "Improvement of compensation mechanism on peak-regulating auxiliary service for thermal power unit with energy saving dispatch,” Heilongjiang Electric Power, vol. 36, no. 3, pp. 194197, Jun. 2014.

[8] XIE Jun, BAI Xing-zhong, GAN De-qiang, "Evaluation and Incentive of Peaking capability of Hydroelectric / Thermoelectric Generators," Journal of Zhejiang University (Engineering Science), vol. 43, no. 11, pp. 2079-2084, Nov. 2009.

[9] XIE Jun, ZHANG Xiao-hua, WU Fu-xia, FU Rong, "Peaking cost allocation using cooperative game theory and engineering concept," Power System Protection and Control, vol. 40, no. 11, pp. 16-23, Jun. 2012.

[10] WANG Ruogu, WANG Jianxue, ZHANG Heng, BAI Xingzhong, “A Cost Analysis and Practical Compensation Method for Hydropower Units Peaking Service,” Automation of Electric Power Systems, vol. 35, no. 23, pp. 41-46, Dec. 2011.

[11] HU Jianjun, HU Feixiong, "A Novel Compensation Mechanism of Remunerative Peak Load Regulation Under Energy-saving Dispatch Framework,” Automation of Electric Power Systems, vol. 33, no. 10, pp. 16-18, May. 2009.

[12] XING Zhenzhong, "Technology Research on Depth Peak Load Cycling of Thermal Power Generator Units," North China Electric Power University, 2013.

[13] DONG Dong, PANG Qinghua, WU Yan, Modern Comprehensive Evaluation Methods and Typical Cases, 2nd ed. Beijing, Tsinghua University Press, 2008, pp. 111-119.

[14] PU Tianjiao, CHEN Naishi, GE Xianjun, WANG Wei, LIU Guangyi, "Research on Evaluation Index System and Synthetical Evaluation Method for Balance of Electric Power and Energy,” Power System Technology, vol. 39, no. 1, pp. 250-256, Jan. 2015. 